\begin{tabular}{llll}
\hline Bentham open & The Open Pain Journal \\
\hline CrossMark & Content list available at: www.benthamopen.com/TOPAINJ/ & $\substack{\text { The } \\
\text { Open Pain } \\
\text { lournal }}$ \\
\hline
\end{tabular}

RESEARCH ARTICLE

\title{
Comparing Effects of Cryotherapy and Transcutaneous Electrical Nerve Stimulation on Signs and Symptoms of Delayed Onset Muscle Soreness in Amateur Athletes
}

\author{
Kazem Malmir, Nastaran Ghotbi ${ }^{*}$, Seyed Mohsen Mir and Behzad Moradi \\ Department of Physiotherapy, School of Rehabilitation, Tehran University of Medical Sciences, Enghelab Ave, Pitch-e- \\ Shemiran, Tehran, Iran
}

Received: July 19, 2017

Revised: August 11, 2017

Accepted: August 16, 2017

\begin{abstract}
:
Background:

Although self-limiting, delayed-onset muscle soreness (DOMS) declines performance of the athletes. The aim of the present study was to compare the effects of repeated use of cryotherapy and transcutaneous electrical nerve stimulation (TENS) on signs and symptoms following hamstring DOMS.
\end{abstract}

\section{Methods:}

This study used a randomized controlled trial design. Thirty-two participants were randomly allocated into a TENS or cryotherapy group. Ten participants were also considered as a control group. Pain, active knee extension range of motion (AROM), triple-hop distance and thigh girth were assessed before, 24, 48 and 72 hours after inducing DOMS in the dominant hamstrings muscle.

\section{Results:}

Two-factor repeated measures analysis of variance showed a significant main effect of time for pain intensity, AROM and triple hop distance $(\mathrm{P}<0.05)$, and main effect of group for pain intensity and $\operatorname{AROM}(\mathrm{P}<0.05)$, and interaction effects of group $\times$ time for pain intensity and AROM $(\mathrm{P}<0.05)$. Post hoc statistical tests showed that mean of pain intensity and AROM was changed by cryotherapy group $(\mathrm{P}<0.017)$.

\section{Conclusion:}

Presence of pain, decreasing AROM and reducing triple hop distance confirmed the induction of DOMS in the hamstrings. Cryotherapy was more effective than TENS for controlling pain and improving AROM after DOMS. Triple hop distance, as a measure of function, was not able to detect dominance of cryotherapy or TENS for controlling DOMS of the hamstrings in spite of repeated use of these interventions.

Keywords: Delayed onset muscle soreness, Cryotherapy, TENS, Injury, AROM, Hamstrings.

\section{INTRODUCTION}

Most of the athletes have experienced delayed onset muscle soreness (DOMS) during their careers, generally following an unaccustomed exercise or eccentric exercise [1,2]. Eccentric exercises may cause micro-injury particularly in the distal musculotendinous junction of the muscles $[1,3]$. The signs and symptoms of DOMS including, pain, edema, increase in passive stiffness, decrease in range of motion (ROM) and impairment of proprioception may commence within 12-24 hours and peak at 48 hours after exercise [4, 5]. Full recovery may last about 10 days [4]. The

\footnotetext{
* Address correspondence to this author at the Department of Physiotherapy, School of Rehabilitation, Tehran University of Medical Sciences, Enghelab Ave, Pitch-e-Shemiran, Tehran, Iran; Tel: +982177535132; Ext: (264); E-mail: nghotbi@tums.ac.ir
} 
problem can range from a simple discomfort to severe disabilities which can reduce athlete's performance or prevent them to participate in sports exercises [4]. Hamstrings muscle suffers frequently from DOMS [6, 7]. Also, hamstrings muscle strains frequently because of eccentric loading imposed on it during repeated extensions in a soccer competition. Eccentric exercises can reduce the risk of strain injury of the hamstrings. But, the same exercises may induce DOMS in the hamstrings if performed repeatedly or the athlete is not prepared for performing exercise [6].

Various mechanisms have been purposed that contribute to DOMS, including lactic acid accumulation, muscle spasm, injury to the muscles and connective tissues, and release of enzymes and inflammation [1]. Accordingly, various methods have been suggested for managing these problems including, usage of NSAIDs and rehabilitation as a whole $[4,8]$. There is no consensus on the effectiveness of the drugs [8]. On the other hand, conservative managements including cryotherapy, ultrasound, electrical stimulation, massage, stretch, immobilization and rest have shown some success [8]. Generally, rest, ice, compression and elevation regimen have been used for managing acute soft tissue injuries. Using the ice in the regimen can decrease the temperature of the tissue and resolve inflammation [1,9]. Improvement of tissue after acute injury is therefore accelerated [10]. A few researches have been conducted on the effects of cryotherapy on DOMS; most of which did not report any significant effect [11 - 13]. These studies used eccentric contractions of elbow flexors for inducing DOMS. They used cryotherapy in different forms including, cold water immersion and ice massage. But, they applied the treatment only one time after induction of DOMS. The limited use may be the reason of the ineffectiveness of cold therapy on DOMS. In the present study, cryotherapy has been applied frequently to assess if it would be more effective in controlling signs and symptoms of DOMS. Different forms of electrical stimulation have also been suggested for managing DOMS [14 - 16]. Widely used transcutaneous electrical nerve stimulation (TENS) has been applied for decreasing pain and inflammatory response associated with DOMS [17, 18]. Similar to cryotherapy, limited use of TENS may not be sufficient to have any effect on the signs and symptoms of DOMS. They used TENS on elbow flexors and only one time. There was no study found which compared effects of the repeated use of cryotherapy and TENS on DOMS of the hamstrings muscles. The aim of the present study, therefore, was to compare the effects of repeated use of cryotherapy and TENS on the signs and symptoms of DOMS of the hamstrings including, pain intensity, active knee extension range of motion (AROM), thigh girth and the distance covered during triple hop test. The authors hypothesized that increasing frequency of application of cryotherapy and TENS could be a more helpful management for DOMS of the hamstrings; also, the protocols used in the current study would be able to determine which of the interventions may be better than the other for controlling signs and symptoms of DOMS.

\section{METHOD}

\subsection{Participants}

Forty-two healthy, amateur male soccer players (age: $26 \pm 3$ yrs.; mass: $73 \pm 5 \mathrm{~kg}$ ), determined by convenient nonprobability sampling method, participated in the current study. They had no lower extremity injury during the previous year. There was no contraindication for using electrical stimulation or icing. No sensitivity to ice or electrical stimulation was observed during the tests. They had not performed any heavy training two weeks before performing the tests. After familiarizing with test procedures, participants signed an inform consent approved by ethics committee of our University Review Board (IRCT ID: IRCT2016100230083N1).

\subsection{Procedures}

Sixteen participants were randomly allocated to each intervention group; TENS or cryotherapy group. Ten participants were considered as control group. Pain intensity, AROM, thigh girth and the distance covered during triple hop test were measured for all participants. DOMS was then induced for the hamstring muscles of the lower extremity that the participant preferred to kick a ball. Pain intensity, AROM, thigh girth and the distance covered during triple hop test were measured again 24, 48 and 72 hours after inducing DOMS. TENS and ice bag were applied to the TENS and cryotherapy groups, respectively. But, no intervention was prescribed for the control group. All measurements were performed by an examiner who was blind to group classification.

Active knee extension test was used for measuring AROM. This test has been shown to be valid for this purpose [19]. The participant was in the supine position on a bed. A box was put below the dominant knee to set the hip joint in 90 degrees of flexion. Fulcrum of a digital goniometer was aligned with the lateral epicondyle of the femur. The fixed and moving arms were extended toward the greater trochanter and lateral malleolus, respectively. The opposite lower extremity was secured in the neutral position on the bed using two straps; one on the anterior superior iliac spine (ASIS) 
and the other on the middle of the thigh. While trying to keep the contact of back of the thigh with the box, the participant was asked to actively extend the thigh gently and report any stretch, discomfort or pain. Two seconds after reporting the first point of discomfort or pain, the angle was recorded [19]. Thigh girth was measured using a flexible meter at three regions; $10 \mathrm{~cm}$ above lateral epicondyle of the femur, middle distance between lateral epicondyle and the greater trochanter of the femur, and below the gluteal fold. Three markers in these regions were used for the next measurements. Pain intensity was measured using a $100 \mathrm{~mm}$ visual analogue scale (VAS) before, 24, 48 and 72 hours after inducing delayed onset muscle soreness for the hamstrings. The participant was asked to mark his perceived pain intensity on the VAS during active knee extension test. Triple hop distance was used for assessing function. The participant was asked to perform three successive hops using the dominant lower extremity. The distance covered between the big toe at the start point and posterior of the heel at the end of the third hop was considered as the distance traveled during this test. The test would be repeated if the other lower extremity touched the ground.

For inducing DOMS in the hamstrings, the participant was in the kneeling position on a bed and the hands were by the sides (Fig. 1). Distal of the legs was secured using a strap. The participant was asked to bend forward from the knees as further as possible. He was instructed not to bend the hip joints or the spine. In this way, the hamstrings had to control, eccentrically, the lowering of the thigh, pelvic and trunk segments as a rigid lever. The procedure consisted of 12 sets including, six repetitions. Ten seconds and $2 \mathrm{~min}$ rest were allowed between each repetition and set, respectively [20].

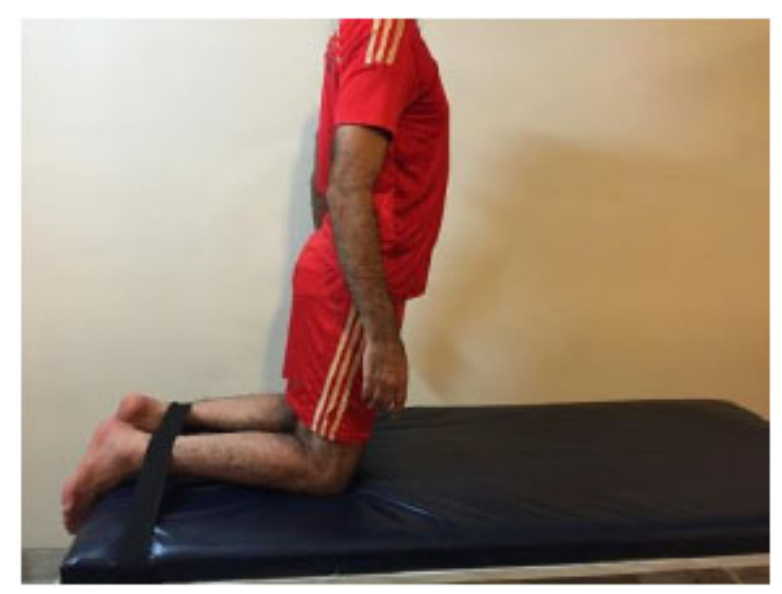

Fig. (1). Positioning of the participant for inducing delayed onset hamstrings muscle soreness.

\subsection{Cryotherapy Intervention}

The participant was in the prone position. A wet towel was put on the hamstrings muscle. Ice bag containing mixed pieces of ice and water was put on the towel and covered by another towel. The intervention lasted for $20 \mathrm{~min}$. The cryotherapy protocol consisted of three repetitions daily (8-hour intervals) for three consecutive days. The size of the ice bag was chosen according to the contour of the hamstrings. Any adverse effect of icing was monitored by the researchers in the first session.

\subsection{TENS Intervention}

Transcutaneous electrical nerve stimulation was applied by an ITO stimulator (Model 1207, ITO, Co., Ltd, Japan). The participant was in the prone position. One pair of rubber electrodes was placed longitudinally on the most painful site of the musculotendinous junction of the hamstrings in the lower one-third of the muscle [21]. TENS was applied once in a day for three consecutive days. Frequency, pulse width and duration were set at $110 \mathrm{~Hz}, 200 \mu$ s, and $20 \mathrm{~min}$, respectively. Intensity was increased up to a sensory level, that is, the participant felt a paresthesia with no muscle contraction $[18,21]$.

\subsection{Statistical Analysis}

SPSS version 22 was used for analyses. Significant level of 0.05 was considered for these analyses. Distribution of data was coinciding with the normal distribution as determined by Kolmogorov-Smirnov test. One factor analysis of variance (ANOVA) was used to show any significant difference for means of anthropometric variables across three 
groups and also to show any significant difference for means of dependent variables across three groups before interventions. Separate $3 \times 4$ (three groups; four measurement times) mixed model ANOVAs were conducted to assess main effects of group and time, and interaction effect of group $\times$ time for means of pain intensity, AROM, thigh girth and triple hop distance. Post hoc Bonferroni adjustment was used when necessary; adjusted significant level was considered for this purpose.

\section{RESULTS}

There was not any significant difference across groups for anthropometric characteristic of the participants (Table 1). No significant difference was observed for distribution of the dependent variables before interventions (Table 2).

Table 1. Anthropometric characteristics (without decimal places) of the participants in different groups.

\begin{tabular}{|c|c|c|c|c|c|}
\hline & Cryotherapy(16) & TENS(16) & Control(10) & \multirow{2}{*}{$\mathbf{F}_{(2,39)}$} & \multirow{2}{*}{ P value } \\
\hline & Mean \pm SD & Mean \pm SD & Mean \pm SD & & \\
\hline Age (yrs.) & $26 \pm 3$ & $25 \pm 3$ & $26 \pm 3$ & 0.29 & 0.75 \\
\hline Body mass (kg) & $72 \pm 5$ & $72 \pm 5$ & $76 \pm 6$ & 1.61 & 0.21 \\
\hline Height (cm) & $175 \pm 5$ & $174 \pm 5$ & $178 \pm 6$ & 1.37 & 0.27 \\
\hline
\end{tabular}

Table 2. Mean and standard deviation (SD) of different parameters before intervention across groups.

\begin{tabular}{|c|c|c|c|c|c|}
\hline & Cryotherapy(16) & TENS(16) & Control(10) & \multirow{2}{*}{ F $_{(2,39)}$} & \multirow{2}{*}{ P value } \\
\cline { 2 - 4 } & Mean \pm SD & Mean \pm SD & Mean \pm SD & & \\
\hline Pain intensity (mm) & $1.56 \pm 2.42$ & $1.15 \pm 2.82$ & $1.80 \pm 2.44$ & 1.62 & 0.21 \\
\hline Distal thigh girth (cm) & $41.3 \pm 2.52$ & $40.06 \pm 2.19$ & $40.62 \pm 2.56$ & 1.07 & 0.35 \\
\hline Middle thigh girth (cm) & $48.82 \pm 2.62$ & $48.06 \pm 2.29$ & $48.61 \pm 3.23$ & 0.34 & 0.71 \\
\hline Proximal thigh girth (cm) & $56.16 \pm 3.26$ & $55.36 \pm 3.07$ & $56.10 \pm 3.00$ & 0.30 & 0.74 \\
\hline AROM (deg) & $153.3 \pm 10.82$ & $150.83 \pm 8.33$ & $154.19 \pm 7.98$ & 0.48 & 0.62 \\
\hline Triple hop distance (m) & $4.29 \pm 15$ & $4.33 \pm 0.11$ & $4.31 \pm 0.18$ & 0.31 & 0.74 \\
\hline
\end{tabular}

Significant main effects of time $\left(F_{3,156}=94.38, P=0.001, \eta=0.88\right)$ and group $\left(F_{2,156}=5.28, P=0.009\right.$, $\left.\eta=0.21\right)$, and interaction effect of group $\times$ time $\left(F_{6,156}=3.12, P=0.009, \eta=0.20\right)$ were found for pain intensity. A post-hoc adjustment using Bonferroni test showed that there was a significant difference for the mean of pain intensity between cryotherapy and control groups $(\mathrm{P}<0.017)$, but, mean of pain intensity between TENS group and cryotherapy group $(\mathrm{P}>0.017)$ and between TENS group and control group $(\mathrm{P}>0.017)$ was not significantly different. Also, a pairwise comparison showed that mean of pain intensity was significantly increased progressively after inducing DOMS until 48 hours $(\mathrm{P}<0.0125)$ but, started to decrease 72 hours after inducing DOMS $(\mathrm{P}<0.0125)$ (Fig. 2).

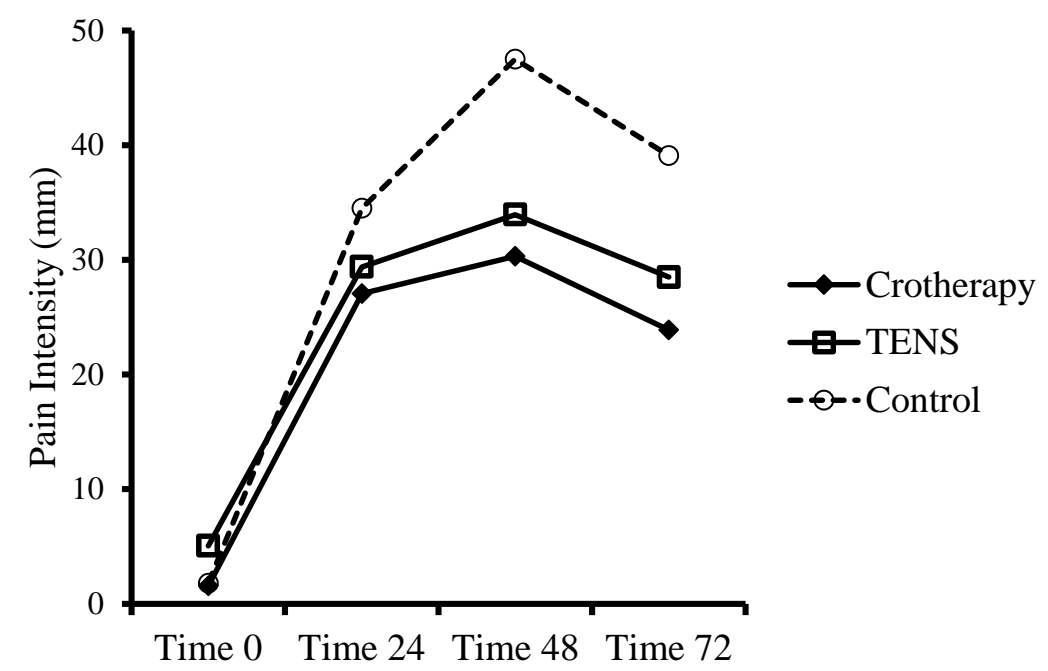

Fig. (2). Mean of pain intensity across groups and measurement times. 
Significant main effect of time $\left(\mathrm{F}_{3,156}=4.48, \mathrm{P}=0.005, \eta=0.81\right)$ and group $\left(\mathrm{F}_{2,156}=4.59, \mathrm{P}=0.012, \eta=0.81\right)$ were found for AROM. But, no interaction effect of group $\times$ time $\left(F_{6,156}=4.97, P=0.87, \eta=0.29\right)$ was observed for AROM. Bonferroni test showed that there was a significant difference for the mean of pain intensity between cryotherapy and TENS groups $(\mathrm{P}<0.017)$, but, mean of pain intensity between cryotherapy group and control group $(\mathrm{P}>0.017)$ and between TENS group and control group $(\mathrm{P}>0.017)$ was not significantly different. A pairwise comparison revealed that mean of AROM decreased 48 hours $(\mathrm{P}<0.0125)$ and 72 hours $(\mathrm{P}<0.0125)$ after inducing DOMS, but, the decreasing trend stopped between 48 hours and 72 hours after inducing DOMS $(\mathrm{P}>0.0125)$ (Fig. 3 ).

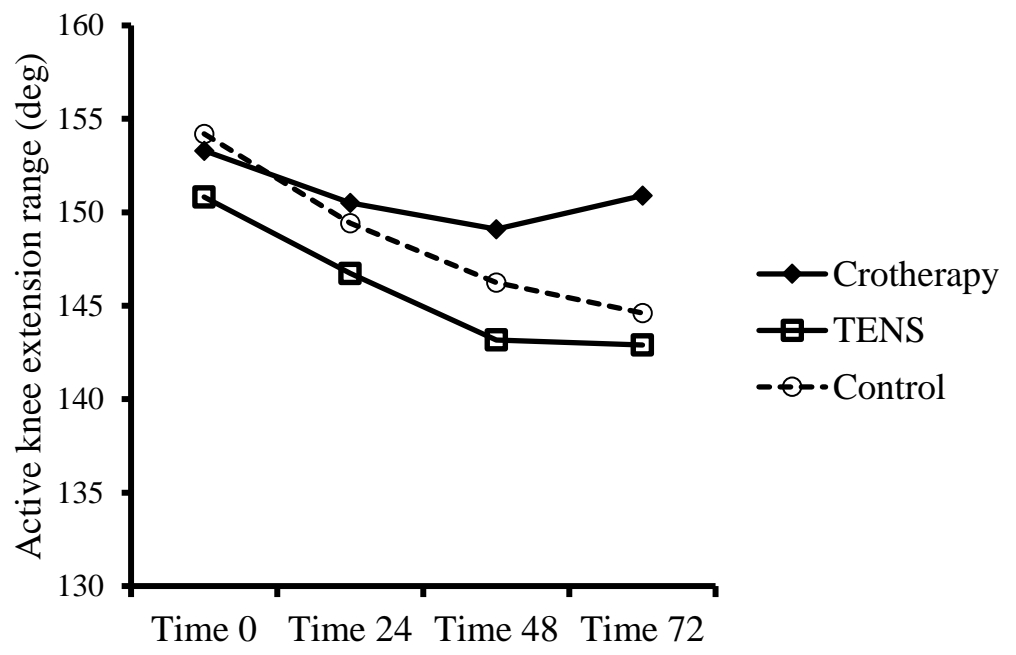

Fig. (3). Mean of active knee extension range across groups and measurement times.

There was not any significant main effect of time $\left(F_{3,156}=0.33, P=0.80, \eta=0.03\right)$, group $\left(F_{2,156}=1.53, P=0.23, \eta=0.07\right)$ or interaction effect of group $\times$ time $\left(\mathrm{F}_{6,156}=1.73, \mathrm{P}=0.13, \eta=0.12\right)$ for the thigh girth in the distal region due to DOMS. No significant main effect of time $\left(\mathrm{F}_{3,156}=0.74, \mathrm{P}=0.54, \eta=0.06\right)$, group $\left(\mathrm{F}_{2,156}=0.11, \mathrm{P}=0.90, \eta=0.01\right)$ or interaction effect of group $\times$ time $\left(\mathrm{F}_{6,156}=0.40, \mathrm{P}=0.88, \eta=0.03\right)$ was found for the thigh girth in the middle region due to DOMS. No significant main effect of time $\left(F_{3,156}=0.78, P=0.51, \eta=0.06\right)$, group $\left(F_{2,156}=0.29, P=0.75, \eta=0.01\right)$ or interaction effect of group $\times$ time $\left(\mathrm{F}_{6,74}=1.05, \mathrm{P}=0.40, \eta=0.08\right)$ was found for the thigh girth in the proximal region due to DOMS.

A significant main effect of time $\left(F_{3,156}=19.71, P=0.001, \eta=0.62\right)$ was found for triple hop distance. There was not any significant main effect of group $\left(F_{2,156}=1.69, P=0.20, \eta=0.08\right)$ or interaction effect of group $\times$ time $\left(F_{6,156}=0.74\right.$, $\mathrm{P}=0.62, \eta=0.06)$ for triple hop distance. A pairwise comparison revealed that mean of triple hop distance showed significantly a successive decrease, 24 hours $(\mathrm{P}=0.001), 48$ hours $(\mathrm{P}=0.001)$ and 72 hours $(\mathrm{P}=0.001)$ after inducing DOMS; but, the mean between 48 hours and 72 hours after DOMS was not significantly different $(\mathrm{P}=0.25)(\mathrm{Fig}$. 4).

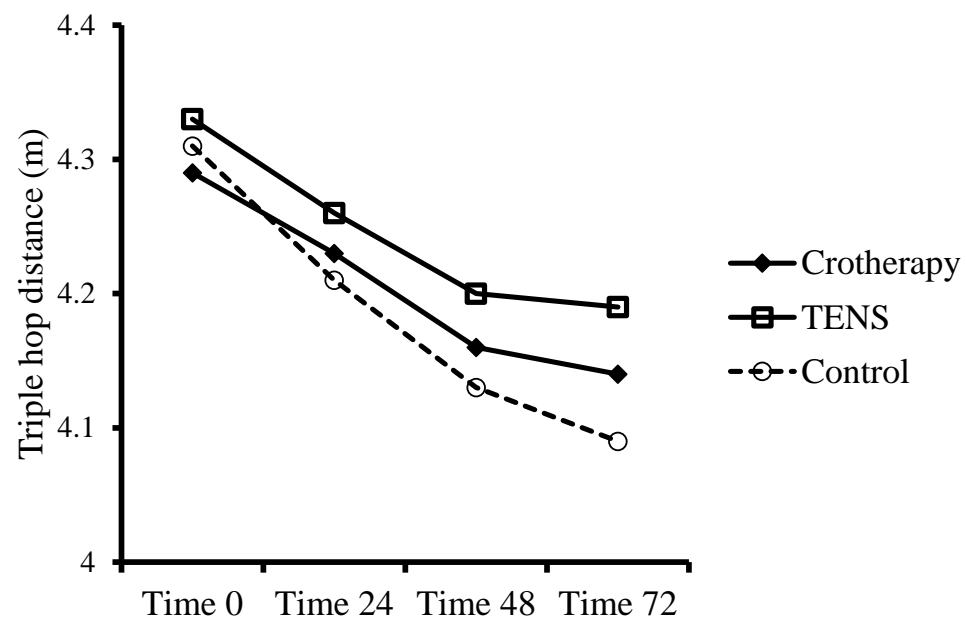

Fig. (4). Mean of triple hop distance across groups and measurement times. 


\section{DISCUSSION}

The objective of the present study was to compare the effects of cryotherapy and TENS on the problems associated with DOMS of the hamstrings including, pain intensity, AROM, thigh girth and the distance covered during triple hop test. Results showed that pain intensity was progressively increased until 48 hours after inducing DOMS. Pain intensity was then decreased, but only by cryotherapy. TENS had no effect on pain intensity. AROM, which was affected only by cryotherapy, decreased only after 48 hours; but, the decrease was stopped after 72 hours after inducing DOMS. Triple hop distance decreased progressively until 48 hours and stopped then 72 hours after inducing DOMS but, the changes was not affected by cryotherapy or TENS. Girth of the thigh was not influenced by DOMS.

Decrease in pain intensity in the current study is in agreement with the study of Macedo et al. (2015) who used ice as an intervention to determine if it had an effect on pain threshold, assessed by an algometer on the lateral epicondyle of the humerus. They reported that the threshold had been increased due to icing [22]. The finding of the present study was also in agreement with Oakley et al. (2013) who applied ice three times daily on the hamstrings after eccentric exercise and found an improvement in pain [3]. Morita et al. (2004) did not report any change in perceived pain using ice bag after inducing DOMS in elbow flexors. But, they applied 20 min only one time after eccentric exercise [12]. The TENS parameters used in the current study are considered as a stimulation in the sensory level. In the sensory level, pain may be decreased according to the gate control theory of Melzack and wall. That is, analgesia may be present only at the time of stimulation. As the stimulation is interrupted, pain may be reappeared [23]. Deneger et al. (1992) reported a decrease in pain after inducing DOMS in elbow flexor muscles using TENS for one session [21]. The conflicting results may be due to the fact that they measured pain immediately after application of TENS. In the present study, pain was being measured in a long interval relative to the application of TENS. Pain may have been returned, therefore, by the time of measurements. Given this long time interval, the pain gate control may be disregarded as the effective mechanism of relieving pain induced by ice application as well. Other mechanisms of cryotherapy such as endogenous opioids and counter irritation, therefore, may have decreased pain intensity [24]. Pain reduction using cryotherapy may also be produced by vasoconstriction and control of swelling [25]. No measurable swelling was generated in the current study because of consistency of thigh girth after inducing DOMS. Improvement of pain, therefore, may have not resulted by vasoconstriction and control of swelling.

Active knee extension test is a common tool to assess knee ROM after acute injuries of the hamstrings [19]. In the current study, active knee extension range decreased after 48 hours but, the decreasing trend did not continue until 72 hours after inducing DOMS in the hamstrings. Cryotherapy had a role in this trend but, TENS had no influence on the range of active knee extension. The finding was in agreement with Denegar et al. (1992) who applied TENS and ice massage on the biceps brachialis after inducing DOMS and reported an increase in the elbow ROM only by cold and not by TENS [21]. Oakley et al. (2013) applied ice on the hamstrings after inducing DOMS and found an improvement in pain; but, they did not observe any improvement in the range of motion of the knee extension [3]. The conflicting findings may be due to different protocols of inducing DOMS in the hamstrings. They used an eccentric exercise using a dynamometer. Also, they focus on just a cryotherapy and a control group. Knee extension ROM may be restricted in the terminal range due to spasm induced by DOMS of the hamstrings [26]. Interrupting decreasing trend of AROM obtained by cryotherapy can be related to the decrease of pain and/or spasm. The later did not assess in the current study.

Triple hop test was reported to be a suitable tool for examining strength and power in the lower extremities [25]. This test can thus reflect function in this way. Results in the present study showed that triple hop distance decreased until 48 hours, but, the trend was stopped 72 hours after inducing DOMS in the hamstrings. DOMS may have led to altered joint mechanics, muscular structure and connective tissues in the hamstrings [1]. Neither TENS nor cryotherapy was effective in decreasing attenuation of triple hop distance resulted from DOMS. Many factors contribute to perform a successful triple hop. Presence of some pain and decrease of terminal active knee extension range of motion may have not been enough to impair this function.

Thigh circumferences in different regions were not changed due to hamstrings DOMS. This may be opposite with studies that shown some swelling due to induction of DOMS. Probably, more aggressive eccentric exercises could have induced swelling in the thigh region. Both interventions, particularly cryotherapy, may have prevented any probable formation of swelling. Crystal et al. (2013) studied the effect of cryotherapy on hamstrings recovery following induction of DOMS and did not report any effect of icing on swelling of the thigh [26].

Except for pain and AROM, cryotherapy or TENS had not a priori for better subsiding signs and symptoms 
associated with DOMS. A more strenuous eccentric exercise may provide a better condition to differentiate, which of them would be more helpful. Combining management protocols, for example massage or stretching accompanying with cryotherapy, or using electrical stimulation with low level muscle contractions such as, brief intense TENS may provide more options for rehabilitation of DOMS. Also, the present study is limited for generalizing the results because of the lack of a group for which the interventions are applied only one time. This design could help to differentiate between one and multiple sessions of intervention.

\section{CONCLUSION}

DOMS occurred in the present study confirmed by the presence of pain, decreasing AROM and reducing triple hop distance. Only cryotherapy could decrease pain intensity permanently after induction of DOMS in the hamstrings. Pain may decrease just during the application of TENS. Active range of motion and triple hop distance, as measures of function in the lower extremities, did not get affected by cryotherapy or TENS. Comparing to previous researches, increasing frequency of application of these interventions did not result in a better management of signs and symptoms associated with DOMS.

\section{ETHICS APPROVAL AND CONSENT TO PARTICIPATE}

This research was approved by Ethical committee of the University Review Board (IRCT ID: IRCT2016100230083N1).

\section{HUMAN AND ANIMAL RIGHTS}

No animals were used in this research. All research procedures followed were in accordance with the ethical standards of the committee responsible for human experimentation (institutional and national), and with the Helsinki Declaration of 1975 , as revised in 2008 . (http://www.wma.net/en/20activities/10ethics/10helsinki/).

\section{CONSENT FOR PUBLICATION}

Not applicable.

\section{CONFLICT OF INTEREST}

The authors declare no conflict of interest, financial or otherwise.

\section{ACKNOWLEDGEMENTS}

This study was supported by Research Deputy, Tehran University of Medical Sciences. We would like to thank all the participants for participating in this trial.

\section{REFERENCES}

[1] Cheung K, Hume P, Maxwell L. Delayed onset muscle soreness: treatment strategies and performance factors. Sports Med 2003; 33(2): 145-64.

[http://dx.doi.org/10.2165/00007256-200333020-00005] [PMID: 12617692]

[2] Hilbert JE, Sforzo GA, Swensen T. The effects of massage on delayed onset muscle soreness. Br J Sports Med 2003; $37(1)$ : 72-5. [http://dx.doi.org/10.1136/bjsm.37.1.72] [PMID: 12547748]

[3] Oakley ET, Pardeiro RB, Powell JW, Millar AL. The effects of multiple daily applications of ice to the hamstrings on biochemical measures, signs, and symptoms associated with exercise-induced muscle damage. J Strength Cond Res 2013; 27(10): $2743-51$. [http://dx.doi.org/10.1519/JSC.0b013e31828830df] [PMID: 23364294]

[4] Nelson N. Delayed onset muscle soreness: is massage effective? J Bodyw Mov Ther 2013; 17(4): $475-82$. [http://dx.doi.org/10.1016/j.jbmt.2013.03.002] [PMID: 24139006]

[5] Vaile J, Halson S, Gill N, Dawson B. Effect of hydrotherapy on the signs and symptoms of delayed onset muscle soreness. Eur J Appl Physiol 2008; 102(4): 447-55. [http://dx.doi.org/10.1007/s00421-007-0605-6] [PMID: 17978833]

[6] de Loës M, Dahlstedt LJ, Thomée R. A 7-year study on risks and costs of knee injuries in male and female youth participants in 12 sports. Scand J Med Sci Sports 2000; 10(2): 90-7.

[http://dx.doi.org/10.1034/j.1600-0838.2000.010002090.x] [PMID: 10755279]

[7] Jönhagen S, Németh G, Eriksson E. Hamstring injuries in sprinters. The role of concentric and eccentric hamstring muscle strength and flexibility. Am J Sports Med 1994; 22(2): 262-6. 
[http://dx.doi.org/10.1177/036354659402200218] [PMID: 8198197]

[8] Connolly DA, Sayers SP, McHugh MP. Treatment and prevention of delayed onset muscle soreness. J Strength Cond Res 2003; 17(1): 197-208.

[PMID: 12580677]

[9] Cleak MJ, Eston RG. Delayed onset muscle soreness: mechanisms and management. J Sports Sci 1992; 10(4): 325-41. [http://dx.doi.org/10.1080/02640419208729932] [PMID: 1518094]

[10] Kennet J, Hardaker N, Hobbs S, Selfe J. Cooling efficiency of 4 common cryotherapeutic agents. J Athl Train 2007; 42(3): 343-8. [PMID: 18059988]

[11] Bleakley C, McDonough S, MacAuley D. The use of ice in the treatment of acute soft-tissue injury: a systematic review of randomized controlled trials. Am J Sports Med 2004; 32(1): 251-61. [http://dx.doi.org/10.1177/0363546503260757] [PMID: 14754753]

[12] Howatson G, Gaze D, van Someren KA. The efficacy of ice massage in the treatment of exercise-induced muscle damage. Scand J Med Sci Sports $2005 ; 15(6): 416-22$. [http://dx.doi.org/10.1111/j.1600-0838.2005.00437.x] [PMID: 16293154]

[13] Morita S, Sakurai Y, Matoba H. effect of ice pack on muscle injury induced by eccentric. Bulletin of the Faculty of Education. Yamaguchi University 2004; 54: 75-80

[14] Yackzan L, Adams C, Francis KT. The effects of ice massage on delayed muscle soreness. Am J Sports Med 1984; 12(2): 159-65. [http://dx.doi.org/10.1177/036354658401200214] [PMID: 6742292]

[15] Tourville TW, Connolly DA, Reed BV. Effects of sensory-level high-volt pulsed electrical current ondelayed-onset muscle soreness. J Sports Sci 2006; 24(9): 941-9. [http://dx.doi.org/10.1080/02640410500357226] [PMID: 16882628]

[16] Butterfield DL, Draper DO, Ricard MD, Myrer JW, Schulthies SS, Durrant E. The effects of high-volt pulsed current electrical stimulation on delayed-onset muscle soreness. J Athl Train 1997; 32(1): 15-20. [PMID: 16558426]

[17] Denegar CR, Perrin DH, Rogol AD, Rutt RA. Influence of transcutaneous electrical nerve stimulation on pain, range of motion, and serum cortisol concentration in females experiencing delayed onset muscle soreness. J Orthop Sports Phys Ther 1989; 11(3): 100-3. [http://dx.doi.org/10.2519/jospt.1989.11.3.100] [PMID: 18796921]

[18] Craig JA, Cunningham MB, Walsh DM, Baxter GD, Allen JM. Lack of effect of transcutaneous electrical nerve stimulation upon experimentally induced delayed onset muscle soreness in humans. Pain 1996; 67(2-3): 285-9. [http://dx.doi.org/10.1016/0304-3959(96)03124-7] [PMID: 8951922]

[19] Norris C, Matthews M. Inter-tester reliability of a self-monitored active knee extension test. J Bodyw Mov Ther 2005; 9(4): 256-9. [http://dx.doi.org/10.1016/j.jbmt.2005.06.002]

[20] Brockett CL, Morgan DL, Proske UW. Human hamstring muscles adapt to eccentric exercise by changing optimum length. Med Sci Sports Exerc 2001 May 1; 33(5): 783-90. [http://dx.doi.org/10.1097/00005768-200105000-00017]

[21] Denegar CR, Perrin DH. Effect of transcutaneous electrical nerve stimulation, cold, and a combination treatment on pain, decreased range of motion, and strength loss associated with delayed onset muscle soreness. J Athl Train 1992; 27(3): 200-6. [PMID: 16558162]

[22] Macedo LB, Josué AM, Maia PH, Câmara AE, Brasileiro JS. Effect of burst TENS and conventional TENS combined with cryotherapy on pressure pain threshold: randomised, controlled, clinical trial. Physiotherapy 2015; 101(2): 155-60. [http://dx.doi.org/10.1016/j.physio.2014.07.004] [PMID: 25306231]

[23] Johnson M. Transcutaneous Electrical Nerve Stimulation. In: Electrotherapy: Evidence based practice. 12th ed. Edinburgh: Churchill Livingstone 2008; pp. 253-96 [http://dx.doi.org/10.1093/acrefore/9780199975839.013.137]

[24] Saeki Y. Effect of local application of cold or heat for relief of pricking pain. Nurs Health Sci 2002; 4(3): 97-105. [http://dx.doi.org/10.1046/j.1442-2018.2002.00112.x] [PMID: 12153407]

[25] Olaogun M, Parkins GE, Boama MO. Comparative effects of transcutaneous electrical nerve stimulation, cryotherapy and placebo on pain, swelling and trismus following third molar tooth. Nigerian J Med Rehabil 2010; 23(15): 38-43. [NJMR].

[26] Cleak MJ, Eston RG. Delayed onset muscle soreness: mechanisms and management. J Sports Sci 1992; 10(4): 325-41. [http://dx.doi.org/10.1080/02640419208729932] [PMID: 1518094]

(C) 2017 Malmir et al.

This is an open access article distributed under the terms of the Creative Commons Attribution 4.0 International Public License (CC-BY 4.0), a copy of which is available at: (https://creativecommons.org/licenses/by/4.0/legalcode). This license permits unrestricted use, distribution, and reproduction in any medium, provided the original author and source are credited. 